Психология. Журнал Высшей школы экономики.

2021. T. 18. № 3. C. 491-505. DOI: 10.17323/1813-8918-2021-3-491-505

\title{
Cmamьu
}

\section{«БЕСТЕЛЕСНОСТЬ» ЛИЧНОСТИ В УСЛОВИЯХ ВИРТУАЛЬНОЙ КУЛЬТУРЫ}

\author{
A.Н. ИСАЕВА \\ ${ }^{a}$ Национальный исследовательский университет «Высшая школа экономики», 101000, Россия, \\ Москва, ул. Мясницкая, д. 20
}

\begin{abstract}
Резюме
Статья посвящена проблематизации виртуальной жизни личности в аспекте телесности в условиях тотальной цифровизации социальных и личных отношений. Проблемность этой области стала особенно ощутима в период эпидемии COVID-19. В работе предложена категория «виртуального Другого», который одновременно является результатом активности личности в виртуальности и специфическим объектом ее отношений. В контексте развития Модели топологии жизни Е.Б. Старовойтенко предложены дополнения в виде виртуального и предметно-фигуративного пространств жизни личности. В этих координатах раскрывается особенная проблематика жизненной активности личности. Анализ статей и рефлексивных заметок, появившихся по следам мировой самоизоляции 2020 г., а также ряда других источников, посвященных цифровизации, позволяет сосредоточить сформулированные проблемы в рамках трех сфер личностной активности: коммуникации, деятельности и отношений личности. В работе осмысляются такие проблемы, как потеря телесности в виртуальной коммуникации - недоступность целостного облика Другого и собственной телесной самопрезентации, фрагментарность невербальных проявлений, недоступность контакта глаз, невозможность подхватить диалог на основе чуткого телесного со-присутствия в едином пространстве. Рассматриваются возможные причины Zoom fatigue. Мы анализируем психологические искажения в результате неестественной коммуникации в Zoom'e - все одновременно смотрят на меня (или нет?), и я непрерывно вижу себя в числе других. Реализация отношений в виртуальном пространстве делает коммуникацию с Другим бестелесной и непрерывной и исключает важнейшие паузы, в которых развивается внутренний диалог с Другим. Наряду с реальным, телесным Другим и редуцированным «внутренним Другим» развивается «виртуальный Другой», который должен стать предметом психологических исследований. Виртуальность - это новое, мало освоенное пространство индивидуальной жизни. Пока что оно безграничное, инвазивное и исключающее телесность. На данный момент в культуре нет сформированных способов персонального освоения виртуального пространства и разрешения противоречий, порождаемых личностной активностью в нем.
\end{abstract}

Ключевые слова: виртуальная культура, виртуальное пространство, виртуальная реальность, цифровая культура, цифровизация, Zoom, усталость от Zoom, тело, телесность, воплощенность, Интернет, онлайн, дистанционная работа, карантин, изоляция, COVID-19. 
Рубеж XX-XI вв. характеризуется развитием цифровой экономики и массовой цифровизацией культуры и общества. Нарождающиеся трансформации личности, социальных отношений и различных сфер деятельности в условиях виртуальной культуры постепенно становятся предметом изучения в гуманитарных науках (Абдрахманова и др., 2019; Радаев, 2018; Солдатова, Погорелов, 2018; Солдатова и др., 2017). Актуальной и горячо обсуждаемой темой становится проблематика цифровизации образования. Психологические исследования виртуальной жизни личности постепенно переходят от проблематики интернет-зависимости к разработке категории «клипового мышления» (Исаева, Малахова, 2015), изучению феноменов фаббинга ${ }^{1}$ и зависимости от гаджетов (Крюкова, Екимчик, 2019; Chotpitayasunondh, Douglas, 2016), кибербуллинга (Бочавер, Хломов, 2014; Tokunaga, 2010), специфики онлайн-обучения и дистанционного фриланса, разработке технологий иммерсивного обучения в виртуальной среде (Southgate, 2020). В мире спорят о виртуальной культуре: анализируют вызовы, оценивают риски, аргументируют возможности, защищают перспективы. Внезапно мировые события 2020-2021 гг., связанные с эпидемией COVID-19, разворачивают процессы цифровизации в полную силу, и социальная, и профессиональная жизнь множества людей на всем земном шаре стремительно переходит в виртуальную форму.

В результате даже то поколение, которое социологи называют «цифровыми аборигенами»² (Prensky, Bennett, Радаев), переживает довольно сильную тревогу в связи с необходимостью решать профессиональные и учебные задачи в «тотальном онлайне».

Данная работа посвящена проблематизации виртуальной жизни личности. В статье намечены новые категории «виртуального Другого» $и$ «виртуального пространства жизни личности», предложены дополнения в модель топологии жизни Е.Б. Старовойтенко (2015). Представлен анализ принципиальной специфики виртуального пространства индивидуальной жизни ввиду дефицита телесного присутствия личности. ${ }^{3}$

Мы предлагаем рассматривать виртуальное пространство жизни личности в контексте развития модели топологии индивидуальной жизни Е.Б. Старовойтенко (Там же). Данная модель построена на основе текстов философии и психологии жизни (А. Бергсон, М.М. Бахтин, С.Л. Рубинштейн, М.К. Мамардашвили). В настоящей статье модель топологии жизни представлена как одна из основных теоретико-методологических опор во взгляде на пространство индивидуальной жизни. Модель включает следующие пространства: духовное, культурное, социальное, внутреннее, трансличностное, телесности,

\footnotetext{
${ }^{1}$ Поглощенность гаджетами во время непосредственной коммуникации с другими.

${ }^{2}$ Родившиеся в 1982-2000 гг.

${ }^{3}$ Текст во многом является результатом размышлений автора в период самоизоляции, рефлексии собственной профессиональной деятельности в виртуальной среде и обсуждений данной проблематики со студентами и преподавателями Центра фундаментальной и консультативной персонологии Национального исследовательского университета «Высшая школа экономики».
} 
деятельности, влияний и вкладов, Высшего. Они выделены преимущественно по критерию доминирующих релевантных объектов, результатов персональной активности личности, границ каждого пространства с другими пространствами. Например, пространство телесности образовано витальностью, физической силой и глубинными ресурсами тела, обликом и наружностью личности, телесными способностями и задатками, телесной экспрессией, глубинными связями личности с природой, данностью тела себе и другим. В пространстве культуры основными релевантными объектами являются культура, к которой принадлежит личность, декларируемые ценности и глубинные влияния культуры, культурные практики, основные культурные ресурсы деятельности, познания и самопознания личности. В пространстве деятельности сосредоточены конкретные действия и занятия личности, способы осуществления и персональные результаты деятельности, каноны и авторитеты личности в деятельности. В социальном пространстве аккумулированы ближние и дальние другие, род и семья, социум, социальные связи, социальный статус, признание или отчуждение личности другими людьми и т.д. Трансличностное пространство отличается от социального тем, что его доминирующими объектами являются действенные «отраженности» (Е.Б. Старовойтенко, В.А. Петровский) значимых других в личности, а также ее собственное «присутствие» в других через их неосознаваемые идентификации и глубинные отношения к ней.

Логично предположить, что специфическими элементами виртуального пространства личности являются цифровые объекты: как оцифрованные тексты, образы, картины, фильмы, музыка, так и создаваемые внутри виртуального пространства специфичные объекты: виртуальные сообщества и средства коммуникации (форумы, чаты, блоги, мессенджеры с характерными средствами выражения эмоций, виртуальные почтовые ящики, программы для видеоконференций), электронные кошельки и электронные счета, виртуальные среды документооборота и экосистемы для самых разнообразных сфер деятельности, Интернет вещей (от «умного дома» до сложной промышленности), виртуальные игры, а также специфические медиа-объекты и сетевые явления типа интернет-мемов, троллинга и кащенизма, кибербуллинга, медиавирусов, флуда, спама и т.д. Это пространство населено виртуализированными Другими - пользователями, разработчиками, субъектами активного обращения с элементами цифрового мира. Виртуальное пространство жизни теснее всего граничит с такими пространствами, как культурное, социальное, деятельностное, и дистанцировано от пространства телесности. Более того, осуществление индивидуальной жизни преимущественно в виртуальном пространстве на данном этапе развития технологий исключает и замещает телесную жизнь личности. Разрыв между виртуальным и телесным пространством жизни частично нивелируется через разработку технологий виртуальной и дополненной реальности.

Полагаем, что в модели топологии жизни могут быть выделены и интегрированы в особую сферу жизни предметные компоненты различных пространств, образуя предметно-фигуративное пространство. Его основными 
объектами являются физическое пространство - от космоса до места, которое занимает индивидуальное тело в каждый момент времени, местности и ландшафты, конкретные топосы, характеризующие индивидуальную жизнь вещи, способы освоения пространства и передвижения в нем, освоение новых пространств, масштаб и топологию предметно-фигуративного существования личности. Представляются интересными психологические феномены возникновения жестких границ между телесным и предметно-фигуративным пространством (отчуждение пространства в навязчивых страхах, слабая витальность или вынужденная иммобилизация, уход во внутреннее пространство жизни), а также проявления чрезмерно проницаемых границ (неодушевленные селф-объекты, «расширенное тело» М. Маклюэна, Т. Алкемайера и др.).

Виртуальное пространство существует на основе предметно-фигуративного пространства и «человеческого» (субъектного) среза культурного пространства (нужны конкретные предметы - гаджеты, сервера, источники питания и люди, действующие с ними), а также имитирует предметно-фигуративное пространство, замещает его или, в лучшем случае, оказывается в него «вложенным». Отношения между культурным и виртуальным мирами нуждаются в психологической проблематизации и глубоком осмыслении. В этом плане направляющей для нас является категория «виртуальная культу$p a »$ с акцентом на ее личностные аспекты.

Не менее важна для нас категория «виртуального Другого», появляющаяся на концептуальном пересечении виртуального и трансличностного пространств. В рафинированном виде он существует в тех случаях, когда предметно-фигуративное и телесное пространства оказываются исключены из отношений. В моделировании данной категории мы опираемся на модель генеза отношений Е.Б. Старовойтенко (Старовойтенко, Исаева, 2010; Старовойтенко, 2015), а именно на идею о том, что в развитии отношения к значимому Другому в личности формируется внутренний эквивалент Другого или «внутренний Другой»: интроект, «инкорпорированный» объект, результат идентификации, или «отраженный» Другой. «Внутренний Другой» является неизбежным результатом и условием отношений личности с его реальным прототипом. Психическая ткань этого процесса «овнутрения» образована психическими функциями: ощущением, восприятием, памятью, мышлением, воображением, эмоциями, рефлексией, а также желаниями, мотивами, ценностями и смыслами личности. Совершенно естественной и необходимой в формировании внутреннего объекта является глубинная активность личности: неосознаваемое присвоение себе Другого, проективные идентификации, интуитивное схватывание сущностных свойств Другого, предчувствие его тени, проекции родительских фигур, проекции символических фигур и т.д. Причем чем более значим другой, тем интенсивнее будет глубинная активность. Вся душевная активность Я, устремленная к Другому, реализуется в условиях непосредственного взаимодействия личности с реальным Другим. Однако если взаимодействие реализуется исключительно в виртуальном пространстве, а в качестве «реального» Другого индивидуальной психике доступен лишь «цифровой» Другой, формирование внутреннего объекта 
все равно происходит. И здесь речь идет не о социальном пространстве в онлайне, а о полноценном отражении в личности виртуального облика, «аватара» другого человека в редуцированных внешних условиях. Позже мы вернемся к проблеме виртуального Другого и специфике развития значимых отношений за пределами предметно-фигуративного и телесного пространств.

Условно исследовательские проблемы о «бестелесности» человека в условиях «виртуальной культуры» можно обозначить как специфику коммуникации, деятельности и отношений личности. Остановимся подробнее на этих сферах, рассматривая их как образующие виртуального пространства и акцентируя проблемность его границ и взаимосвязей с пространствами культуры, телесности, деятельности и трансличностным пространством.

\section{Специфика коммуникации личности в виртуальном пространстве}

Коммуникация посредством, например, массовой видеоконференции обладает определенными особенностями: мы с собеседниками как бы находимся вместе, но не «в месте». Мы не разделяем единое предметно-фигуративное пространство, но общим для нас является нигде не локализованное, временно организованное и часто незащищенное виртуальное пространство. Мы никак не присутствуем в нем своим телом, и другой человек нам дан в своей очень редуцированной телесности - в виде «цифровой личины». Речь идет о том, что если во время виртуальной видеокоммуникации просодика ${ }^{4}$ и экстралингвистика ${ }^{5}$ в невербальном поведении другого еще могут быть нам доступны, то телесная экспрессия личности, неосознаваемые телесные реакции и активность тела в пространстве практически не выражены, не видны. В свою очередь, прикосновения, рукопожатия, дружеские похлопывания и объятия, организация предметно-фигуративного пространства коммуникации, телесная дистанция, телесное владение пространством, запахи, подлинный визуальный контакт вообще остаются за пределами этого общения. Если же речь идет о чате, переписке, то мы начинаем улавливать совершенно другую невербальность общения.

На наш взгляд, один из интереснейших рефлексивных опытов работы с учебной группой в формате видеоконференций принадлежит профессору антропологии из университета Нотр-Дам (США) Сьюзен Д. Блюм (Blum, 2020). Она отмечает, что офлайн-работа с «живой» группой отличается своей ритмикой коммуникаций: синхронными высказываниями и подхватыванием фраз, интуициями, когда другой готов говорить, или пониманием, что другой нуждается в вопросе. Все имеет значение: поза, взгляд, поворот головы в обращении к другому, дыхание и одновременный смех. В формате видеоконференции, как правило, включен только динамик говорящего и транслируется видео плохого качества. Видеотрансляции большинства участников группы в итоге оказываются просто отключены. «Таким образом, все коммуникативные

\footnotetext{
${ }^{4}$ Просодика - громкость голоса, тембр, высота, сила ударения.

${ }^{5}$ Экстралингвистика - всхлипывания, смешки, кашель, вздохи, вдохи, сопение, смех, плач.
} 
знаки, на которые полагаются телесные люди, истончены, уплощены, сделаны более трудоемкими или полностью невозможными. Но мы все равно их интерпретируем» (Ibid.). Автор акцентирует внимание на дефицитах виртуальных семинарских занятий, однако мы в свою очередь отметим важнейшие телесные знаки, которых, помимо всего перечисленного выше, очень не хватает на виртуальных лекциях: взгляды - задумчивые или рассеянные, внимающие или отсутствующие, сомневающиеся, вопрошающие, проблематизированные, сосредоточенные, обращенные в себя, скептичные, озаренные. И глухая тишина в Zoom, решительно противоположная той звенящей тишине, которая бывает при обсуждении особенно значимых тем в живой, телесной аудитории. Полагаем, что в предельной форме эти дефициты можно прожить во время записи онлайн-курсов. Как быть с тем, что за холодным объективом ты еще не чувствуешь присутствие адресата? С.Д. Блюм также отмечает, как много времени уходит впустую на организацию локальных обсуждений в видеоконференции: «Мертвое время смертельно опасно для ритмов» (Ibid.).

Специфическая коммуникация в виртуальном пространстве определяет проблемное развитие виртуальной деятельности и виртуальных отношений.

\section{Специфика деятельности в виртуальном пространстве}

В данной области по-новому раскрываются идеи отечественной школы деятельности. В частности, такие аспекты, как внешние предметные свойства субъекта деятельности (А.Н. Леонтьев), инструментальная структура деятельности и ее интериоризация во внутренний план жизни (Л.С. Выготский, А.Н. Леонтьев, В.Д. Шадриков), предметное действие как первичный акт по отношению к познавательной активности личности (С.Л. Рубинштейн). Телесность (индивидность), пространственное расположение, предметная активность субъекта деятельности оказываются источником затруднений в деятельности, когда исключены из нее.

В 2020 г. в исследованиях на стыке гуманитарных и компьютерных наук появляется описание феномена Zoom fatigue ${ }^{6}$ - комплексного проживания усталости от Zoom'a (Cranford, 2020). Те, кому пришлось в период карантина усиленно работать в формате массовых видеоконференций, хорошо знакомы с быстро возникающим истощением активности, потерей личной укорененности в деятельности, временны́ми затратами, которые по опыту деятельности в офлайне несоизмеримы со временем, затраченным на онлайн-встречи, семинары или совещания.

Дж. Бейленсон предполагает, что указанная усталость появляется в результате асинхронности взаимодействия - от зависаний программы, усугубляемых качеством связи, до едва заметных постоянных «лагов». Речь идет

\footnotetext{
${ }^{6}$ Zoom - программа для видеоконференций с подключением до 500 человек одновременно. В зависимости от выбранного формата работы на экране (в несколько страниц) могут одновременно транслироваться видео всех присутствующих на конференции участников, включая видео пользователя.
} 
о синхронизации обмена фразами в диалоге и невербальной коммуникации: «Если в эту систему вводится задержка, даже если эта задержка составляет всего миллисекунды, подсознательно наш мозг все равно регистрирует проблему и работает усерднее» (Wiederhold, 2020). Б. Видерхольд также сообщает, что увеличенное лицо другого человека может неосознанно восприниматься как угроза агрессии, а параллельный чат является дополнительным источником стресса. Б. Видерхольд предлагает отключать камеру и микрофон в профессиональной коммуникации, чтобы не подвергать участников конференции избыточной стимуляции, а также смотреть в камеру, а не на монитор для достижения контакта глаз. Однако зрительный контакт в видеоконференции невозможен по определению. А отключенные камера и микрофон пользователя полностью исключают его из со-бытия с другими участниками. Необходимо заметить, что феномен усталости от Zoom впервые становится отрефлексирован и обозначен в качестве проблемы именно в 2020 г., когда Zoom начинает массово использоваться для профессиональной деятельности.

Поведенческий аналитик Л. Дадли отмечает дилемму визуального контакта: чтобы позволить другому почувствовать его, мне необходимо смотреть в камеру, но чтобы принять этот взгляд от другого, я вынуждена «забрать» свой взгляд у другого и переключиться на монитор. При этом я понимаю, что мой деловой партнер делает то же самое и что мы никак не сможем смотреть друг другу в глаза одновременно. «Во время личного разговора жесты человека (например, резкий вдох, наклон вперед или зрительный контакт с кем-то) указывают нам на то, что он собирается заговорить» (Callahan, 2020). Но если в видеоконференции участвует десять или более человек, эти сигналы оказываются потеряны, разговор становится несвязанным и чаще люди предпочитают не разговаривать (Ibid.).

Таким образом, совместная деятельность, осуществляемая в виртуальном пространстве жизни, оказывается изматывающей ввиду недоступности телесных сигналов другого, асинхронности и затруднений в коммуникации.

Вероятно, усталость может быть вызвана также специфической конфигурацией контакта в Zoom и положением субъекта в нем. В групповом взаимодействии в предметно-фигуративном пространстве я обычно вижу, кто смотрит на меня. В основном смотрят на говорящего и направленное «ви́дение» выступает самостоятельной деятельностью всех участников коммуникации. В раскладке Zoom одновременно все смотрят на всех, и хотя я не переживаю визуального контакта, я могу ощущать себя перманентным объектом взглядов других и доподлинно не знаю, кто и в какой момент времени смотрит именно на меня, даже когда я говорю. У кого-то усталость может быть вызвана также непрерывным слежением за собственным лицом и его экспрессией.

Возможно, неестественным является постоянное ви́дение себя-субъекта в Zoom-раскладке остальных участников видеоконференции. В непосредственном взаимодействии мы преимущественно находимся в «переживающем Эго» (У. Джемс) и видим перед собой только других. Лишь иногда мы обращаемся к «наблюдающему Эго» и осознаем себя в качестве действующего субъекта в кругу других субъектов. Постоянное нахождение в переживающем и в наблюдающем 
Эго может создавать избыточное «напряжение самосознания», эффектом которого может быть неви́дение, неслышание и в целом дереализация других собеседников в связи с усиленной Я-центрацией.

Другая проблема реализации профессиональной деятельности в виртуальном пространстве была связана с дефицитом предметно-фигуративного пространства по обе стороны веб-камеры. А. Крисман рассказывает о трудностях детских психологов в период карантина: «Многие специалисты по детскому психическому здоровью сообщают, что для проведения сеанса им необходимо найти тихое место в ванной, туалете или подвале» (Chrisman, 2020, p. 180). Но этим проблемы не исчерпывались: «...дети часто пропадают из зоны видимости веб-камеры во время сеанса. Связанное с этим чувство потери невербальных сигналов, столь важных для работы детских терапевтов, оставило у многих ощущение того, что они оказали неадекватную помощь» (Ibid., p. 180181). Дж. Хакер с соавт. исследовали твиты в период карантина и отметили, что участия в онлайн-встрече недостаточно, чтобы человек почувствовал себя где-то еще. Фактически виртуальное пространство даже не создает иллюзии перемещения, владения, деятельности в расширенном предметно-фигуративном пространстве (Hacker et al., 2020).

Еще одна проблема осуществления деятельности, которая затрагивается в исследовании Дж. Хакера с соавт.и которую мы хотели бы подробнее обсудить, связана с отсутствием в виртуальном пространстве устойчивых границ. Авторы отметили феномен размытия границ между профессиональной деятельностью и личной жизнью. В этом исследовании многие респонденты также говорят о стеснении в связи с открытием для коллег жилого пространства вместе с теми, кто его населяет. Фактически виртуальность - это пространство, которое имеет очень непостоянные инварианты: плавающие ссылки на видеоконференции, легко меняющиеся аккаунты и псевдонимы, закрывающиеся сайты, удаляющиеся паблики в социальных сетях, динамичные интерфейсы, новые инструменты социального общения, множественность личности в своих проявлениях в этом пространстве и т.д. Утрачивая тело и устойчивое физическое пространство, личность теряет какую-то большую часть своей субъектности в этом поле информационных событий, будто бы уже не являясь их подлинно опосредующим, действующим лицом.

Поскольку я никак не присутствую в этом пространстве телесно, я могу сохранять анонимность (при определенных навыках - полную анонимность), это может сдвигать границы моей этики, идентичности, самовыражения. Однако даже персонализированное виртуальное взаимодействие отличается этой слабостью границ. Например, находясь с кем-то в приватном чате, я не могу быть уверена, что наш контакт конфиденциален: скриншот переписки в два клика отправляется собеседником в какой-то коллективный чат или вывешивается в открытый паблик. Поэтому подлинная приватность партнерства и диалога в виртуальном пространстве возможна в кругу только близких лиц, с которыми есть совместный опыт границ.

В виртуальной деятельности личность погружается во вслушивание и напряженную внешнюю коммуникацию, при этом не успевает улавливать 
отраженность своих действий в других и вообще может отдаляться от ощущений собственного тела. В «бестелесном» взаимодействии я как бы становлюсь бестелесным субъектом и, как следствие, перестаю в достаточной степени контактировать со своими границами - не понимаю, где они нарушаются другими, перестаю отстаивать их, недостаточно хорошо чувствую, где пролегают границы другого. Это похоже на утрату «заземления», которое так трудно удерживать непрерывно, погружаясь в виртуальность.

Дж. Хакер с соавт. пишут о дефиците естественных случайностей жизни, которые рождаются только лишь на базе действий в предметно-фигуративном мире: «Физическая кофемашина дает хороший шанс встретить новых людей» (Hacker et al., 2020).

Исследованы также проблемы присутствия в виртуальной деятельности. Например, работа Я. Чжао, А. Ван, И. Сан посвящена факторам, которые удерживают студента на изучении онлайн-курса (МООС'а). К выделенным факторам относится необходимость коммуницировать внутри курса (студенты получают больше положительных эмоций от общения и продолжают МOOC); богатство медиавозможностей (Daft, Lengel, 1984) и состояние потока, проживаемое через телеприсутствие и социальное присутствие (Zhao et al., 2020).

Исследование Э. Саутгейт посвящено проблематике иммерсивного обучения и раскрывает некоторые закономерности телесного и предметно-фигуративного пространств в качестве необходимых условий для ощущения присутствия и действенности в виртуальном пространстве: «Ощущение "присутствия” зависит от места и иллюзии правдоподобия. Иллюзия места включает в себя человека, который психологически чувствует, что он присутствует в виртуальной среде, используя свое тело для восприятия окружающего его мира, осматривая и поворачиваясь, дотягиваясь до объектов и манипулируя ими, а также слушая, как в реальном мире. Иллюзия правдоподобия воспринимает события в виртуальной среде так, как если бы они происходили на самом деле, потому что виртуальная среда реагирует на действия участников и может спонтанно вызывать реакции участников» (Southgate, 2020, p. 38).

Виртуальность проживания, становясь аспектом культуры личности, приобретает свою специфику в мире значимых отношений личности с другими людьми или в трансличностном пространстве.

\section{Специфика отношений личности в виртуальном пространстве}

Мы полагаем, что лучше всего динамика отношений личности с Другим в телесном и предметно-фигуративном пространствах раскрывается в работах М.М. Бахтина, М. Мерло-Понти и Е.Б. Старовойтенко. Поэтому в данном разделе мы вновь опираемся на модель генеза отношений (Старовойтенко, Исаева, 2010), возвращаемся к проблематике «взгляда» и топологии телесности (Бахтин, 1979; Станковская, 2014; Старовойтенко, 2015) в контексте эстетики живописного и словесного творчества и обращаемся к некоторым исследованиям в этой области, проведенным в период карантина-2020. 
М.М. Бахтин раскрывает внутреннюю динамику эстетического восприятия другого. Личность обладает индивидуальным местом, единственным и незаменимым, оно обеспечивает уникальный избыток ви́дения другого. «Избыток ви́дения - почка, где дремлет форма и откуда она и развертывается как цветок. Но чтобы эта почка развернулась цветком завершающей формы, необходимо, чтобы избыток моего ви́дения восполнял кругозор созерцаемого другого человека, не теряя его своеобразия» (Бахтин, 1979, с. 24). Эстетическое восприятие формируется из вживания с Другим: «Стать на его место, как бы совпасть с ним»- и последующего возвращения в себя: «Только с этого места материал вживания может быть осмыслен этически, познавательно или эстетически» (Там же, с. 25). В свою очередь Я обладает дефицитным ви́дением своего облика: «Моя наружность, то есть все без исключения экспрессивные моменты моего тела, переживается мною изнутри; лишь в виде разрозненных обрывков, фрагментов, болтающихся на струне внутреннего самоощущения...» (Там же, с. 27). В текстах М.М. Бахтина подчеркивается особая, экзистенциальная роль индивидуальных места, пространства и тела. Особое понимание телесности в феноменологии отношений М. Мерло-Понти реконструировано Е.Б. Старовойтенко в ее модели диалогичного отношения Я - Другой. «В отношение к Другому, обладающему телесностью и видимостью, вступает Я, обладающее видимым и видящим телом» (Старовойтенко, 2017, с. 418). Динамика восприятия Другого также включает в себя вживание в него и возвращение к себе, диалектику видящего и видимого. Эта динамика очень созвучна процессам формирования внутреннего объекта, описанным в модели генеза жизненных отношений Е.Б. Старовойтенко (Старовойтенко, Исаева, 2010; Старовойтенко, 2015). В пространстве виртуальности она обретает совершенно иную специфику, изучение которой определяет новую перспективу данной модели.

Во-первых, избыток ви́дения больше не формируется за счет телесно-пластических свойств Другого и предметно-фигуративного контекста. В онлайнпереписках этот избыток кочует от телесности в реальном пространстве к смыслам и посланиям текста, многоточиям и точкам, смайлам, паузам в ответах, опечаткам. Вероятно, как в чатах, так и в онлайн-конференциях порождение избытка ви́дения смещается с индивидуальной впечатленности объектом на погруженность в объект собственных фантазий и глубинных содержаний. Затрудняется как вживание в объект, так и возвращение к себе, если в коммуникации потерян внутренний контакт со своим местом и телом. Во-вторых, нивелируется позиция «индивидуального места». Онтологически у меня остается индивидуальное место, но в видеоконференции мы все обладаем равными временны́ми местами в виртуальном пространстве. И таким образом дихотомия видимого и видящего уплощается, сглаживается, перестает быть настолько выраженной. В этой ситуации мое представление себя-для-другого не такое уж пустое и безжизненное, если я нахожусь в непрерывной Я-центрации. В то же самое время я не становлюсь для другого оформленной пластической ценностью и как бы «пустею» для него, поскольку он тоже переживает избыточную Я-центрацию. 
Другая проблема заключается в том, что с развитием технологий меняются доступность и частота реального взаимодействия личности со значимыми объектами. Это неизбежно влечет изменения в процессах и эффектах формирования «внутреннего другого». До развития Интернета и мобильной связи контакты между людьми были дискретны, особенно в становящихся отношениях. Время вынужденной разлуки со значимым Другим было заполнено активностью восстановления облика и поведения другого в памяти, воображении, переживании, проживании желаний, проецировании тревог и символических фигур, рефлексии, обращений к Другому во внутренних диалогах и письмах. Невероятно большую ценность имела каждая встреча с Другим. В этих «паузах» протекали процессы формирования и развития внутреннего эквивалента Другого. Безусловно, внутренние объекты формируются и сейчас, но все цивилизованное человечество практически лишено этих необходимых пауз. В данный момент виртуальное пространство делает Другого легко и постоянно доступным в любой точке земного шара, однако в этом случае я лишаюсь проживания нашего реального, телесного соприсутствия в его и своей жизни. «Хотя технологии сделали мир меньше, они не привели к "смерти расстояния”» (Hacker et al., 2020). Как влияет на развитие отношений новая специфика формирования внутренних значимых объектов личности? Насколько они устойчивы, достоверны, целостно воспринимаемы и субъектны для меня? Противоречат ли друг другу «внутренний Другой» и «виртуальный Другой» и как они соотносятся с реальными свойствами своего прототипа? Можно ли полноценно «встать в отношение» к виртуальному Другому? Полагаем, что все эти исследовательские проблемы обретают сейчас особенную остроту.

Телесность ускользает не только из персональных, но и общественных отношений, конституирующих социальное пространство жизни. За счет развития средств связи мы ежедневно вступаем в сотни коммуникаций, которые в большинстве своем бестелесны. И дело даже не в том, хватает ли нам теплых телесных отношений или телесных практик, а в том, из какого количества контактов мы исключили свое тело и насколько это органично или противоестественно для нашей телесной природы и социальной сущности. Возможно, в современности уже можно распознать конкретные компенсаторные процессы. Технологии развиваются настолько стремительно, что проблема виртуальности бытия становится антропологической, биологической, социокультурной и экзистенциально-личностной.

Становление виртуальной культуры и ее гениальные плоды открывают небывалые возможности, но вместе с тем мы сталкиваемся с огромными, пока ничем не восполнимыми дефицитами и последствиями наступающей «бестелесности» личности. Вторичный интеллект в основном научился компенсировать «заброшенную телесность» в различных культурных практиках, но это не делает ее интегрированной в основные русла современной человеческой жизни. Мы телесные существа по своей природе: Эго и сознание личности формируются из телесного, активно движущегося и действующего психоида; чувства приходят через контакт с телом, а в основе познания лежит деятель- 
но-практический акт в предметном мире. На наш взгляд, подлинная компенсация возможна при возвращении телесной жизни личности в ее бурно развивающийся виртуальный мир (в культурной перспективе это станет возможно), через сближение виртуального, телесного и предметно-фигуративного пространств индивидуальной жизни.

\section{Литература}

Абдрахманова, Г. И., Вишневский, К. О., Гохберг, Л. М., Дранев, Ю. Я., Зинина, Т. С., Ковалева, Г. Г., Лавриненко, А. С., Мильшина, Ю. В., Назаренко, А. А., Рудник, П. Б., Соколов, А. В., Суслов, А. Б., Токарева, М. С., Туровец, Ю. В., Филатова, Д. А., Черногорцева, С. В., Шматко, Н. А., Гершман, Н. А., Кузнецова, Т. Е., Кучин, И. И. (2019). Что такое цифровая экономика? Тренды, компетенции, измерение. Доклад к ХХ Апрельской международной научной конференции по проблемам развития экономики и общества, Москва, 9-12 апреля 2019 г. М.: Издательский дом Высшей школы экономики. https://issek.hse.ru/news/261078389.html

Бахтин, М. М. (1979). Эстетика словесного творчества. М.: Искусство.

Бочавер, А. А., Хломов, К. Д. (2014). Кибербуллинг: травля в пространстве современных технологий. Психология. Журнал Высшей школь экономики, 11(3), 178-191.

Исаева, А. Н., Малахова, С. А. (2015). Клиповое мышление: психологические дефициты и альтернативы. Мир психологии. Научно-методический журнал, 84(4), 177-191.

Крюкова, Т. Л., Екимчик, О. А. (2019). Фаббинг как угроза благополучию близких отношений. Консультативная психология и психотерапия, 3, 61-76.

Радаев, В. В. (2018). Миллениалы на фоне предшествующих поколений: эмпирический анализ. Социологические исследования, 3, 15-33. https://doi.org/10.7868/S0132162518030029

Солдатова, Г. У., Рассказова, Е. И., Нестик, Т. А. (2017). Цифровое поколение России: компетентность и безопасность. М.: Смысл.

Солдатова, Е. Л., Погорелов, Д. Н. (2018). Феномен виртуальной идентичности: современное состояние проблемы. Образование и наука, 20(5), 105-124. https://doi.org/10.17853/19945639-2018-5-105-124

Станковская, Е. Б. (2014). От взгляда Другого к другому взгляду на себя: опыт герменевтики. Мир психологии. Научно-методический журнал, 80(4), 97-106.

Старовойтенко, Е. Б. (2015). Персонология: жизнь личности в культуре. М.: Академический проект. Старовойтенко, Е. Б. (2017). Продуктивность диалогичного отношения Я - Другой. Психология. Журнал Высшей школь экономики, 14(3), 408-432. https://doi.org/10.17323/1813-8918-2017-3-408-432

Старовойтенко, Е. Б., Исаева, А.Н. (2010). Роль противоречий в жизни личности. Мир психологии. Научно-методический журнал, 2, 230-241.

Ссылки на зарубежные источники см. в разделе References после англоязычного блока.

Исаева Анастасия Николаевна - старший преподаватель, Центр фундаментальной и консультативной персонологии, департамент психологии, факультет социальных наук, Национальный исследовательский университет «Высшая школа экономики», кандидат психологических наук.

Сфера научных интересов: персонология, методология психологии личности, модели жизненных отношений личности, принцип оппозиций в гуманитарном знании, моделирование личностной рефлексии, герменевтика, мультипрофильное консультирование.

Контакты: aisaeva@hse.ru 


\title{
The "Disembodiment" of the Personality in the Context of Virtual Culture
}

\author{
A.N. Isaeva ${ }^{a}$ \\ ${ }^{a}$ HSE University, 20 Myasnitskaya Str., Moscow, 101000, Russian Federation
}

\begin{abstract}
The article is devoted to the problematization of the virtual life in the aspect of embodiment in the context of the total digitalization of social and personal relationships. These problems have become especially noticeable due to isolation during the COVID-19 epidemic. The category of the Virtual Other proposed in the work. It is the result of the personality's activity in virtuality and the specific object of its relations at the same time. The virtual and subject-figurative spaces of a person's life are proposed as additions in the development of the Life topology model (E.B. Starovoytenko). A special problematic of the person's life activity is revealed in these coordinates. An analysis of articles and reflective notes that appeared in the wake of the global self-isolation of 2020, as well as a number of other sources on the current topic of digitalization, allows us to focus the formulated problems within three spheres of personal activity: communication, activity and personal relationships. Possible causes of Zoom fatigue are discussed. We analyze psychological distortions as a result of unnatural communication in Zoom - everyone is simultaneously looking at me (or not?), And I continuously see myself among others. The psychological consequences of "washing out" the body from the virtualized activity are considered: the activity becomes exhausting, dissatisfaction with the work done appears, the sensitivity to one's own psychological boundaries is lost. Realization of relations in virtual space makes communication with the Other disembodied and continuous and excludes the most important pauses in which an internal dialogue with the Other develops. Along with the real, bodily Other and the reduced "inner Other", the "virtual Other" develops, which should become the subject of psychological research. Virtuality is a new, little-developed space of individual life. So far, it is limitless, invasive and excluding corporeality. At the moment in culture there are no formed ways of personal development of the virtual space and the resolution of contradictions generated by personal activity in it.
\end{abstract}

Keywords: digital culture, virtual space, digital space, virtual reality, digitalization, Zoom, Zoom fatigue, body, corporeality, embodiment, internet, online, telecommuting, quarantine, isolation, COVID-19.

\section{References}

Abdrakhmanova, G. I., Vishnevskii, K. O., Gokhberg, L. M., Dranev, Yu. Ya., Zinina, T. S., Kovaleva, G. G., Lavrinenko, A. S., Mil'shina, Yu. V., Nazarenko, A. A., Rudnik, P. B., Sokolov, A. V., Suslov, A. B., Tokareva, M. S., Turovets, Yu. V., Filatova, D. A., Chernogortseva, S. V., Shmatko, N. A., Gershman, N. A., Kuznetsova, T. E., Kuchin, I. I. (2019). Chto takoe tsifrovaya ekonomika? Trendy, kompetentsii, izmerenie. Doklad k XX Aprel'skoi mezhdunarodnoi nauchnoi konferentsii po problemam razvitiya ekonomiki i obshchestva, Moskva, 9-12 aprelya $2019 \mathrm{~g}$. [What is digital economics? Trends, competences, measurement. A report for the XX April International scientific confer- 
ence on the problems of economic and social development, Moscow, April 9-12, 2019]. Moscow: HSE Publishing House. https://issek.hse.ru/news/261078389.html

Bakhtin, M. M. (1979). Estetika slovesnogo tvorchestva [Aesthetics of verbal creativity]. Moscow: Iskusstvo.

Blum, S. D. (2020, April 22). Why we're exhausted by Zoom. Inside Higher Ed. https://www.insidehighered.com/advice/2020/04/22/professor-explores-why-zoom-classes-deplete-her-energy-opinion

Bochaver, A. A., \& Khlomov, K. D. (2014). Cyberbullying: Harassment in the space of modern technologies. Psychology. Journal of the Higher School of Economics, 11(3), 178-191. (in Russian)

Callahan, M. (2020, May 11). 'Zoom fatigue' is real. Here's why you're feeling it, and what you can do about it. Neres@Northeastern. https://news.northeastern.edu/2020/05/11/zoom-fatigue-is-realheres-why-youre-feeling-it-and-what-you-can-do-about-it/

Chotpitayasunondh, V., \& Douglas, K. M. (2016). How "phubbing" becomes the norm: The antecedents and consequences of snubbing via smartphone. Computers in Human Behavior, 63, 918. https://doi.org/10.1016/j.chb.2016.05.018

Chrisman, A. K. (2020). Debate: \#Together despite the distance. Child and Adolescent Mental Health, 25(3), 180-181. https://doi.org/10.1111/camh.12406

Cranford, S. (2020). Zoom fatigue, hyperfocus, and entropy of thought. Matter, 3(3), 587-589. https://doi.org/10.1016/j.matt.2020.08.004

Daft, R. L., \& Lengel, R. H. (1984). Information richness - a new approach to managerial behavior and organizational design. Research in Organizational Behavior, 6, 191-233.

Hacker, J., Brocke, J. V., Handali, J., Otto, M., \& Schneider, J. (2020). Virtually in this together - how web-conferencing systems enabled a new virtual togetherness during the COVID-19 crisis. European Journal of Information Systems, 29(5), 563-584. https://doi.org/10.1080/0960085x.2020.1814680

Isaeva, A. N., \& Malahova, S. A. (2015). Mosaic thinking: psychological deficits and alternatives (spatial focus). Mir Psikhologii. Nauchno-Metodicheskii Zhurnal, 84(4), 177-191. (in Russian)

Kryukova, T. L., \& Ekimchik, O. A. (2019). Fabbing kak ugroza blagopoluchiyu blizkikh otnoshenii [Fabbing as a threat to close relationships]. Konsul'tationaya Psikhologiya i Psikhoterapiya, 3, 61-76.

Radaev, V. V. (2018). Millennials compared to previous generations: an empirical analysis. Sotsiologicheskie Issledovaniya [Sociological Studies], 3, 15-33. https://doi.org/10.7868/S0132162518030029 (in Russian)

Soldatova, E. L., \& Pogorelov, D. N. (2018). Fenomen virtual'noi identichnosti: sovremennoe sostoyanie problemy. Obrazovanie i Nauka [The Education and Science Journal], 20(5), 105-124. https://doi.org/10.17853/1994-5639-2018-5-105-124.

Soldatova, G. U., Rasskazova, E. I., \& Nestik, T. A. (2017). Tsifrovoe pokolenie Rossii: kompetentnost’ $i$ bezopasnost' [The digital generation of Russia: competence and safety]. Moscow: Smysl.

Southgate, E. (2020). Conceptualising embodiment through virtual reality for education. In Proceedings of 6th International Conference of the Immersive Learning Research Network (iLRN 2020) (Article 9155121, pp. 38-45). IEEE. https://doi.org/10.23919/iLRN47897.2020.9155121

Stankovskaya, E. B. (2014). From another's opinion to another view of self: hermeneutics experience. Mir Psikhologii. Nauchno-Metodicheskii Zhurnal, 80(4), 97-106. (in Russian)

Starovoytenko, E.B. (2015). Personologiya: zhizn' lichnosti v kul'ture [Personology: Life of Personality in Culture]. Moscow: Akademicheskii proyect.

Starovoytenko, E. B. (2017). Productivity of the dialogical relationships I - Other. Psychology.Journal of the Higher School of Economics, 14(3), 408-432. https://doi.org/10.17323/1813-8918-2017-3408-432 (in Russian) 
Starovoytenko, E. B., \& Isaeva, A. N. (2010). The role of contradictions in a personality's life. Mir Psikhologii. Nauchno-Metodicheskii Zhurnal, 62(2), 230-241. (in Russian)

Tokunaga, R. S. (2010). Following you home from school: A critical review and synthesis of research on cyberbullying victimization. Computers in Human Behavior, 26(3), 277-287. https://doi.org/10.1016/j.chb.2009.11.014

Wiederhold, B. K. (2020). Connecting through technology during the Coronavirus disease 2019 pandemic: Avoiding “Zoom Fatigue”. Cyberpsychology, Behavior, and Social Networking, 23(7), 437438. https://doi.org/10.1089/cyber.2020.29188.bkw

Zhao, Y., Wang, A., \& Sun, Y. (2020). Technological environment, virtual experience, and MOOC continuance: A stimulus-organism-response perspective. Computers \& Education, 144, Article 103721. https://doi.org/10.1016/j.compedu.2019.103721

Anastasia N. Isaeva - Senior Lecturer, Department for Fundamental and Consulting Personology, Psychological Department, Faculty for Social Sciences, HSE University, PhD in Psychology.

Research Area: personology, methodology of personality psychology, models of life relationships, the principle of oppositions in humanitarian knowledge, modeling of personal reflection, hermeneutics, multi-modal counseling.

E-mail: aisaeva@hse.ru 